\title{
PENGARUH DOSIS PUPUK NPK DAN APLIKASI PUPUK DAUN TERHADAP PERTUMBUHAN BIBIT CABAI KERITING (Capsicum annuum L.)
}

\author{
Astri Wulandari, Kus Hendarto, Tri Dewi Andalasari \& Setyo Widagdo \\ Jurusan Agroteknologi, Fakultas Pertanian, Universitas Lampung \\ Jl. Prof. Soemantri Brojonegoro, No. 1 Bandar Lampung 35145 \\ Email: astrirush10@gmail.com
}

\begin{abstract}
ABSTRAK
Cabai merupakan salah satu komoditas sayuran yang erat dengan kebutuhan masyarakat sehari-hari. Keberhasilan produksi cabai yang berkualitas ditentukan oleh bibit berkualitas. Salah satu upaya pemeliharaan untuk mendapatkan bibit yang berkualitas yaitu dengan pemberian pupuk tambahan. Pupuk yang dapat digunakan yaitu NPK dan pupuk daun. Tujuan penelitian untuk mengetahui dosis pupuk NPK yang menghasilkan pertumbuhan bibit cabai terbaik, mengetahui frekuensi aplikasi plant catalyst yang menghasilkan pertumbuhan bibit cabai terbaik, dan mengetahui interaksi antara dosis pupuk NPK dan frekuensi aplikasi plant catalyst pada pertumbuhan bibit cabai keriting. Penelitian ini dilaksanakan di Kelurahan Sumberejo Kecamatan Kemiling, Bandar Lampung pada bulan Mei sampai dengan bulan Juli 2015. Penelitian menggunakan rancangan perlakuan secara faktorial $(4 \times 3)$ dalam rancangan kelompok teracak sempurna. Dosis pupuk NPK mutiara N0 (tanpa pemupukan), $\mathrm{N}_{1}$ (0,6 g per tanaman), $\mathrm{N}_{2}$ (1,2 g per tanaman), dan $\mathrm{N}_{3}$ (1,8 g per tanaman). Frekuensi pemberian plant catalyst dengan tiga taraf waktu, P0 (tanpa plant catalyst), P1 (satu kali per minggu), P2 (dua kali per minggu) dengan konsentrasi 1,5 g per liter. Bibit dikelompokkan berdasarkan ukuran besar, sedang, dan kecil. Data diolah dengan analisis ragam dan respons pertumbuhan bibit terhadap perlakuan dilihat melalui uji BNT pada taraf 5\%. Hasil penelitian menunjukkan bahwa dosis pupuk NPK 0,6 g per tanaman merupakan dosis paling efisien untuk diberikan terhadap persemaian bibit cabai keriting, pemberian pupuk daun tidak efisien jika diberikan pada persemaian bibit cabai keriting, terdapat interaksi antara dosis NPK dan aplikasi plant catalyst pada diameter batang pada dosis pupuk NPK 0,6 g per tanaman dengan tanpa aplikasi plant catalyst dan bobot basah bibit cabai keriting pada dosis pupuk NPK 0,6 g per tanaman dengan aplikasi plant catalyst 1 kali per minggu. Kelompok bibit dengan ukuran besar sebagai bahan tanam menunjukkan pertumbuhan yang paling baik.
\end{abstract}

Kata kunci: Bibit, cabai, NPK, plant catalyst

\section{PENDAHULUAN}

Komoditas cabai (Capsicum annuum L.) selain dikonsumsi sehari-hari sebagai bahan tambahan pada makanan, berkembangnya industri pengolahan makanan kini banyak yang menggunakan cabai sebagai bahan baku utama. Oleh karena itu cabai menjadi komoditas sayuran unggul bernilai ekonomis tinggi. Produktivitas cabai meningkat cukup cepat, namun pada saat ini dapat dikatakan masih relatif rendah yaitu 0,20-0,33 $\mathrm{kg}$ per pohon atau 6,84 ton per ha cabai basah dimana produktivitas optimal cabai keriting dapat mencapai 1317 ton/ha (Direktorat Pangan dan Pertanian, 2014).

Berdasarkan hal tersebut perlu ditingkatkan dengan inovasi teknologi baru dan perencanaan tanam yang tepat. Salah satu tahap penting dalam penanaman cabai yaitu persemaian. Keberhasilan produksi cabai yang berkualitas ditentukan oleh kesehatan bibit.Untuk mendapatkan bibit yang baik, benih harus disemai dengan langkah-langkah yang baik dan benar sehingga didapatkan bibit yang berkualitas. Menurut Rostini (2011), untuk meningkatkan pertumbuhan bibit sebaiknya dilakukan pemupukan setiap minggu hingga bibit siap dipindahkan. Pupuk yang dapat digunakan yaitu NPK mutiara dan pupuk daun.

Penambahan pupuk NPK biasa dilakukan petani pada persemaian cabai untuk mendapatkan bibit yang berkualitas. Nitrogen dibutuhkan dalam jumlah yang relatif besar pada setiap tahap pertumbuhan, khususnya pada pertumbuhan vegetatif seperti pertumbuhan tunas atau perkembangan batang dan daun (Venita, dkk., 2007). Salah satu pupuk daun yang berperan sebagai pupuk pelengkap yaitu pupuk plant catalyst. Plant catalyst berfungsi meningkatkan kemampuan tanaman menyerap unsur hara dari berbagai pupuk utama seperti Urea, TSP, $\mathrm{KCl}$, ZA, maupun pupuk alami, seperti pupuk kandang, kompos, dan lain-lain sehingga tanaman dapat mencapai produktivitas yang optimal (CNI, 2011). Konsenterasi plant catalyst 1,5 g per liter mampu meningkatkan potensi hasil tanaman sawi. Pada 
konsentrasi tersebut terjadi peningkatan bobot segar tanaman karena meningkatnya lebar daun dan tinggi tanaman (Surtinah, 2006).

Penelitian ini bertujuan untuk mengetahui dosis pupuk NPKyang menghasilkan berpengaruh untuk pertumbuhan bibit cabai terbaik, frekuensi aplikasi plant catalyst yang menghasilkan pertumbuhan bibit cabai terbaik, dan interaksi antara dosis pupuk NPK dan frekuensi aplikasi plant catalyst pada pertumbuhan bibit cabai keriting.

\section{BAHAN DAN METODE}

Penelitian ini dilaksanakan di Kelurahan Sumberejo Kecamatan Kemiling, Bandar Lampung. Penelitian dilaksanakan pada bulan Mei sampai dengan bulan Juli 2015. Alat yang digunakan dalam penelitian ini adalah cangkul, bambu, plastik naungan, penyaring tanah, ember, sekop, nampan, polibag per plastik semaian, penggaris, meteran, timbangan, gelas ukur, sprayer, jangka sorong, dan alat tulis. Bahan yang digunakan dalam penelitian ini yaitu benih cabai keriting varietas Lado F1, tanah top soil, pupuk kandang sapi, arang sekam, pupuk NPK mutiara, pupuk plant catalyst, air, dan furadan.

Metode penelitian menggunakan rancangan perlakuan disusun secara faktorial $(4 \times 3)$ dalam rancangan kelompok teracak sempurna. Dosis pupuk NPK mutiara terdiri dari N0 (tanpa pemupukan), N1 (0,6 g per tanaman), N2 (1,2 g per tanaman), dan N3 (1,8 g per tanaman). Frekuensi pemberian pupuk plant catalyst dengan tiga taraf waktu : P0 (tidak dilakukan penyemprotan), P1 (disemprot 1 kali per minggu), P2 (disemprot 2 kali per minggu) dengan konsentrasi 1,5 $\mathrm{g}$ per liter. Pupuk NPK diberikan sebanyak 3 kali dengan interval pemberian tiap minggu, sedangkan penyemprotan plant catalyst dilakukan 10 hari setelah tanam dan diberikan sesuai dengan frekuensi aplikasi. Bibit dikelompokkan berdasarkan ukuran besar, sedang, dan kecil. Homogenitas ragam antar perlakuan diuji dengan menggunakan uji Bartlett dan aditivitas data diuji dengan menggunakan uji Tukey. Data diolah dengan analisis ragam dan respon pertumbuhan bibit terhadap perlakuan dilihat melalui uji BNT pada taraf 5\%.

Penelitian ini dilaksanakan melalui beberapa tahapan, yaitu pembuatan tempat pembibitan, persiapan media tanam, penanaman benih, penyulaman, pemupukan NPK mutiara, pemupukan plant catalyst, pemeliharaan, pemanenan bibit. Variabel pengamatan meliputi tinggi bibit, jumlah daun, panjang daun, lebar daun, diameter batang, panjang akar, jumlah akar sekunder, bobot basah bibit (bobot akar sampai dengan tajuk) dan bobot kering bibit (bobot akar dan tajuk).

\section{HASIL DAN PEMBAHASAN}

Hasil penelitian (Tabel 1) menunjukkan bahwa pemberian dosis pupuk NPK mutiara berpengaruh nyata terhadap semua variabel pengamatan. Aplikasi pupuk daun tidak berpengaruh nyata terhadap semua varibel pengamatan. Interaksi antara dosis pupuk NPK mutiara dan aplikasi pupuk daun berpengaruh nyata pada diameter bibit dan bobot basah bibit. Hasil pemberian pupuk NPK pada berbagai level dosis berpengaruh nyata

Tabel 1. Rekapitulasi analisis ragam semua variabel pengamatan pengaruh dosis pupuk NPK mutiara dan aplikasi plant catalyst terhadap pertumbuhan bibit cabai keriting.

\begin{tabular}{lcrcr}
\hline \multicolumn{1}{c}{ Variabel pengamatan } & Kelompok & \multicolumn{2}{c}{ Perlakuan } & Interaksi \\
\cline { 3 - 5 } & & NPK & Plant catalyst & \\
\hline Tinggi bibit & $*$ & $*$ & tn & tn \\
Jumlah daun & $*$ & $*$ & tn & tn \\
Panjang daun & $*$ & $*$ & tn & tn \\
Lebar daun & $*$ & $*$ & tn & $*$ \\
Diameter batang & $*$ & $*$ & tn & tn \\
Panjang akar & - & $*$ & tn & tn \\
Jumlah akar sekunder & - & $*$ & tn & $*$ \\
Bobot basah bibit & $*$ & $*$ & tn & tn \\
Bobot kering bibit & $*$ & tn & \\
\hline
\end{tabular}

Keterangan : $*$ = berbeda nyata pada taraf $5 \%, \mathrm{tn}=$ tidak berbeda nyata pada taraf $5 \%$ 
terhadap tinggi bibit dan jumlah daun cabai keriting (Tabel 2). Dosis NPK 0,6 g per tanaman menghasilkan bibit tertinggi dibandingkan dengan dosis NPK lainnya yaitu 19,46 cm. Dosis NPK 0,6 g per tanaman menghasilkan jumlah daun lebih banyak dibandingkan dengan dosis NPK lainnya yaitu 9,92 helai. Perlakuan aplikasi pupuk daun tidak berpengaruh nyata terhadap tinggi bibit dan jumlah daun. Dosis NPK 0,6 g per tanaman menghasilkan daun lebih panjang dibandingkan dengan dosis NPK lainnya yaitu $5,77 \mathrm{~cm}$. Semakin tinggi dosis pupuk NPK, semakin pendek daun bibit cabai keriting. Dosis NPK 0,6 g per tanaman menghasilkan daun lebih lebar dibandingkan dengan dosis NPK lainnya yaitu 2,13 cm (Tabel 3).

Pengaruh pupuk NPK 0,6 g per tanaman dengan tanpa aplikasi plant catalyst menghasilkan diameter batang yang lebih besar dibandingkan perlakuan lain (Tabel 4). Perlakuan pupuk NPK 0,6 g per tanaman dan NPK 1,2 g per tanaman dengan aplikasi plant catalyst satu kali per minggu menghasilkan diameter batang lebih besar dibandingkan dengan perlakuan NPK $0 \mathrm{~g}$ per tanaman dan NPK 1,8 g per tanaman, sedangkan antara perlakuan NPK 0,6 g per tanaman dan NPK 1,2 $\mathrm{g}$ per tanaman menghasilkan diameter batang bibit yang tidak berbeda. Aplikasi plant catalyst tidak memberikan pengaruh yang berbeda terhadap diameter batang.

Hasil penelitian (Tabel 5) menunjukkan bahwa dosis NPK $0 \mathrm{~g}$ per tanaman dan NPK 0,6 g per tanaman menghasilkan akar yang lebih panjang dibandingkan dengan dosis NPK lainnya. Perlakuan aplikasi pupuk daun tidak berpengaruh nyata terhadap panjang akar bibit cabai keriting. Dosis NPK 0,6 g per tanaman menghasilkan jumlah akar sekunder lebih banyak dibandingkan dengan dosis NPK mutiara lainnya yaitu sebanyak 93,15 helai dan bobot kering bibit lebih berat dibandingkan dengan dosis pupuk NPK lainnya yaitu 0,47 g. Perlakuan aplikasi pupuk daun tidak berpengaruh nyata terhadap panjang akar, jumlah akar sekunder, dan bobot kering bibit cabai keriting.

Perlakuan plant catalyst satu kali per minggu dengan dosis pupuk NPK 0,6 g per tanaman menghasilkan bobot basah terbesar dibandingkan dosis NPK $0 \mathrm{~g}$ per tanaman, $1,2 \mathrm{~g}$ per tanaman dan $1,8 \mathrm{~g}$ per tanaman (Tabel 6). Perlakuan dengan tanpa aplikasi plant catalyst dengan pupuk NPK 0,6 g per tanaman menghasilkan bobot basah terbesar dibandingkan dengan perlakuan dosis NPK 0 g per tanaman, 1,2 g per tanaman, dan 1,8 g per tanaman. Aplikasi plant catalyst tidak memberikan pengaruh yang berbeda terhadap bobot basah bibit cabai keriting.

Hasil penelitian (Tabel 1) menunjukkan bahwa pemupukan NPK dengan dosis 0,6 g per tanaman merupakan dosis yang terbaik untuk pertumbuhan bibit cabai keriting. Semakin ditingkatkan dosis NPK yang diberikan cenderung menurunkan pertumbuhan bibit cabai keriting. Media yang digunakan berupa campuran tanah, arang sekam dan pupuk kandang sapi dengan perbandingan 1:1:1 merupakan komposisi media yang

Tabel 2. Pengaruh dosis NPK mutiara dan aplikasi plant catalyst terhadap tinggi bibit dan jumlah daun bibit cabai keriting 3 MSA.

\begin{tabular}{lcc}
\hline \multicolumn{1}{c}{ Perlakuan } & Tinggi bibit $(\mathrm{cm})$ & Jumlah daun (he lai) \\
\cline { 2 - 3 } & \multicolumn{2}{c}{ Nilai tengah } \\
\hline Dosis NPK & $14,54 \mathrm{c}$ & $6,74 \mathrm{~d}$ \\
NPK 0 g per tanaman & $19,46 \mathrm{a}$ & $9,92 \mathrm{a}$ \\
NPK 0,6 g per tanaman & $17,26 \mathrm{~b}$ & $8,78 \mathrm{~b}$ \\
NPK 1,2 g per tanaman & $13,65 \mathrm{c}$ & $7,89 \mathrm{c}$ \\
NPK 1,8 g per tanaman & 1,71 & 0,71 \\
\hline BNT 5\% & $16,27 \mathrm{a}$ & $8,42 \mathrm{a}$ \\
\hline Aplikasi plant catalyst & $15,83 \mathrm{a}$ & $8,17 \mathrm{a}$ \\
Tanpa aplikasi & $16,59 \mathrm{a}$ & $8,42 \mathrm{a}$ \\
Satu kali per Minggu & 1,48 & 0,61 \\
Dua kali per Minggu & & \\
\hline BNT 5\% & & \\
\hline
\end{tabular}

Keterangan: Nilai tengah yang diikuti oleh huruf yang sama pada kolom yang sama tidak berbeda nyata berdasarkan uji BNT pada taraf 5\% 
Tabel 3. Pengaruh dosis NPK mutiara dan aplikasi plant catalyst terhadap panjang dan lebar daun bibit cabai kriting 3 MSA.

\begin{tabular}{|c|c|c|}
\hline \multirow[t]{2}{*}{ Perlakuan } & Panjang daun (cm) & Lebar daun $(\mathrm{cm})$ \\
\hline & \multicolumn{2}{|c|}{ Nilai tengah } \\
\hline \multicolumn{3}{|l|}{ Dosis NPK } \\
\hline NPK 0 g per tanaman & $4,67 \mathrm{bc}$ & $1,78 \mathrm{c}$ \\
\hline NPK $0,6 \mathrm{~g}$ per tanaman & $5,77 \mathrm{a}$ & $2,13 \mathrm{a}$ \\
\hline NPK 1,2 g per tanaman & $5,01 \mathrm{~b}$ & $1,92 \mathrm{~b}$ \\
\hline NPK 1,8 g per tanaman & $4,65 \mathrm{c}$ & $1,79 \mathrm{c}$ \\
\hline BNT 5\% & 0,36 & 1,12 \\
\hline \multicolumn{3}{|l|}{ Aplikasi plant catalyst } \\
\hline Tanpa aplikasi & $4,96 \mathrm{a}$ & $1,91 \mathrm{a}$ \\
\hline Satu kali per Minggu & $5,11 \mathrm{a}$ & $1,92 \mathrm{a}$ \\
\hline Dua kali per Minggu & $5,00 \mathrm{a}$ & $1,88 \mathrm{a}$ \\
\hline BNT 5\% & 0,31 & 0,1 \\
\hline
\end{tabular}

Keterangan: Nilai tengah yang diikuti oleh huruf yang sama pada kolom yang sama tidak berbeda nyata berdasarkan uji BNT pada taraf 5\%

Tabel 4. Pengaruh interaksi dosis NPK mutiara dan aplikasi plant catalyst terhadap diameter batang bibit cabai keriting pada 3 MSA.

\begin{tabular}{lccc}
\hline Perlakuan & $\begin{array}{c}\text { Tanpa aplikasi } \\
\text { Plant catalyst }\end{array}$ & $\begin{array}{c}\text { Aplikasi Plant catalyst } \\
\text { satu kali per minggu }\end{array}$ & $\begin{array}{c}\text { Aplikasi Plant catalyst } \\
\text { dua kali per minggu }\end{array}$ \\
\hline NPK 0 g per tanaman & $2,08 \mathrm{c}$ & $2,16 \mathrm{~b}$ & $2,34 \mathrm{~b}$ \\
NPK 0,6 g per tanaman & $\mathrm{A}$ & $\mathrm{A}$ & $\mathrm{A}$ \\
& $3,05 \mathrm{a}$ & $2,97 \mathrm{a}$ & $2,64 \ldots \ldots \ldots$ \\
NPK 1,2 g per tanaman & $\mathrm{A}$ & $\mathrm{B}$ & $\mathrm{B}$ \\
& $2,48 \mathrm{~b}$ & $2,64 \mathrm{a}$ & $2,49 \mathrm{ab}$ \\
NPK 1,8 g per tanaman & $\mathrm{B}$ & $\mathrm{A}$ & $\mathrm{A}$ \\
& $2,19 \mathrm{bc}$ & $2,05 \mathrm{~b}$ & $2,38 \mathrm{~b}$ \\
\hline BNT 5\% & $\mathrm{B}$ & $\mathrm{B}$ & $\mathrm{A}$ \\
\hline
\end{tabular}

Keterangan: Nilai yang diikuti huruf yang sama (huruf kecil untuk antar kolom dan huruf besar untuk antar baris) tidak berbeda nyata menurut uji BNT 5\%

mampu menyumbangkan sebagian unsur hara yang dibutuhkan tanaman. Arang sekam mengandung hara penting seperti N, P, K, Ca, dan Mg. Tingkat kemasaman arang sekam berkisar antara 6,5 - 7 (Kurniawan, 2014).

Kandungan unsur hara pada pupuk kandang sapi sangat bervariasi, umumnya mengandung bahan organik sebesar $60-70 \%$, kadar $\mathrm{N}$ sebesar $0,4-2,0 \%$, kadar $\mathrm{P}_{2} \mathrm{O}_{5}$ sebesar $0,2-1,62 \%$, kadar $\mathrm{K}_{2} \mathrm{O}$ sebesar 0,1 -
1,50\%, kadar Ca sebesar 1,1 - 7,26\%, kadar Mg sebesar 0,5 - 2,0\%, kadar S sebesar 1,5\%, kadar Fe sebesar $0,1 \%$, kadar B sebesar $0,01 \%$, kadar $\mathrm{Cu}$ sebesar 0,01 $\%$, kadar Mn sebesar 0,03\%, kadar Zn sebesar 0,03\%, kadar $\mathrm{H}_{2} \mathrm{O}$ sebesar 24,5 - 92\%, kadar C organik sebesar $10,00-18,76 \%, \mathrm{C} / \mathrm{N}$ rasio sebesar $14,00-16,90 \%$ (Utama, 2015). Hara tersedia pada media tanam didukung oleh kondisi $\mathrm{pH}$ yang optimal. Berdasarkan 
Tabel 5. Pengaruh dosis NPK mutiara dan aplikasi plant catalyst terhadap panjang akar, jumlah akar sekunder, bobot kering bibit cabai keriting.

\begin{tabular}{lccc}
\hline \multicolumn{1}{c}{ Perlakuan } & Panjang akar $(\mathrm{cm})$ & Jumlah akar sekunder & Bobot kering $(\mathrm{g})$ \\
\cline { 2 - 4 } & & Nilai tengah & \\
\hline Dosis NPK & $11,02 \mathrm{a}$ & $81,82 \mathrm{~b}$ & $0,21 \mathrm{c}$ \\
NPK 0 g per tanaman & $10,49 \mathrm{ab}$ & $93,15 \mathrm{a}$ & $0,47 \mathrm{a}$ \\
NPK 0,6 g per tanaman & $9,53 \mathrm{~b}$ & $81,18 \mathrm{~b}$ & $0,34 \mathrm{~b}$ \\
NPK 1,2 g per tanaman & $7,83 \mathrm{c}$ & $69,44 \mathrm{c}$ & $0,25 \mathrm{c}$ \\
NPK 1,8 g per tanaman & 1,26 & 9,23 & 0,07 \\
\hline BNT 5\% & & & $0,32 \mathrm{a}$ \\
\hline Aplikasi plant catalyst & $9,64 \mathrm{a}$ & $79,89 \mathrm{a}$ & $0,32 \mathrm{a}$ \\
Tanpa aplikasi & $9,34 \mathrm{a}$ & $82,50 \mathrm{a}$ & $0,31 \mathrm{a}$ \\
Satu kali per Minggu & $10,16 \mathrm{a}$ & $81,81 \mathrm{a}$ & 0,06 \\
Dua kali per Minggu & 1,1 & 8,0 & \\
\hline BNT 5\% & & & \\
\hline
\end{tabular}

Keterangan: Nilai tengah yang diikuti oleh huruf yang sama pada kolom yang sama tidak berbeda nyata berdasarkan uji BNT pada taraf 5\%

Tabel 6. Pengaruh interaksi dosis NPK mutiara dan aplikasi plant catalyst terhadap bobot basah bibit cabai keriting

\begin{tabular}{lccc}
\hline Perlakuan & $\begin{array}{c}\text { Tanpa aplikasi } \\
\text { Plant catalyst }\end{array}$ & $\begin{array}{c}\text { Aplikasi Plant catalyst } \\
\text { satu kali per minggu }\end{array}$ & $\begin{array}{c}\text { Aplikasi Plant catalyst } \\
\text { dua kali per minggu }\end{array}$ \\
\hline NPK 0 g per tanaman & $1,51 \mathrm{c}$ & $1,51 \mathrm{c}$ & $1,82 \mathrm{~b}$ \\
NPK 0,6 g per tanaman & $\mathrm{A}$ & $\mathrm{A}$ & $\mathrm{A}$ \\
& $5,28 \mathrm{a}$ & $5,55 \mathrm{a}$ & $3,97 \mathrm{a}$ \\
NPK 1,2 g per tanaman & $\mathrm{A}$ & $\mathrm{A}$ & $\mathrm{B}$ \\
& $3,71 \mathrm{~b}$ & $3,15 \mathrm{~b}$ & $3,47 \mathrm{a}$ \\
NPK 1,8 g per tanaman & $\mathrm{A}$ & $\mathrm{A}$ & $\mathrm{A}$ \\
& $2,21 \mathrm{c}$ & $1,82 \mathrm{c}$ & $3,15 \mathrm{a}$ \\
\hline BNT 5\% & $\mathrm{A}$ & $\mathrm{A}$ & $\mathrm{A}$ \\
\hline
\end{tabular}

Keterangan: Nilai yang diikuti huruf yang sama (huruf kecil untuk antar kolom dan huruf besar untuk antar baris) tidak berbeda nyata menurut uji BNT 5\%

sampel tanah yang telah dianalisis, $\mathrm{pH}$ media yang digunakan yaitu 6,75. Menurut Sumarni (2005), pH tanah mempengaruhi ketersediaan hara bagi tanaman cabai. Pada $\mathrm{pH}<6$ ketersediaan hara $\mathrm{P}, \mathrm{K}, \mathrm{Ca}, \mathrm{C}$, dan $\mathrm{Mo}$ menurun dengan cepat. Pada $\mathrm{pH}>8$ ketersediaan hara $\mathrm{N}, \mathrm{Fe}, \mathrm{Mn}, \mathrm{Bo}, \mathrm{Cu}$, dan $\mathrm{Zn}$ relatif sedikit. Pada $\mathrm{pH}$ 6,57,5 unsur-unsur hara tersedia dalam jumlah cukup banyak untuk tanaman cabai.
Pemberian pupuk NPK mutiara berpengaruh nyata terhadap semua variabel pengamatan diantaranya tinggi bibit dan jumlah daun. Pupuk NPK mutiara mengandung beberapa unsur yaitu $16 \% \mathrm{~N}, 16 \% \mathrm{P}_{2} \mathrm{O}_{5}$, $16 \% \mathrm{~K}_{2} \mathrm{O}, 0,5 \% \mathrm{MgO}$, dan $6 \% \mathrm{CaO}$. Unsur- unsur tersebut lebih banyak diserap oleh tanaman karena kaitannya dengan pertumbuhan tanaman. Aplikasi pupuk NPK mutiara menunjukkan hasil panjang dan lebar daun 
yang optimum pada dosis $0,6 \mathrm{~g}$ per tanaman (Tabel 4) Menurut Nugroho, dkk. (2006), perkembangan atau pertumbuhan melebar yang terjadi pada tanaman disebut pertumbuhan sekunder. Pertumbuhan sekunder terjadi karena tumbuhan memperoleh nutrisi. Nutrisi terdiri atas unsur-unsur tertentu sebagai sumber energi dan sumber materi untuk sintesis berbagai komponen sel yang diperlukan selama pertumbuhan. Berdasarkan hasil pengukuran pada diameter bibit cabai keriting, hasil optimal ditunjukkan pada perlakuan NPK mutiara $0,6 \mathrm{~g}$ per tanaman dengan tanpa aplikasi plant catalyst. Hal tersebut menunjukkan bahwa nutrisi yang diperlukan untuk pertumbuhan optimal bibit cabai keriting cukup dengan pemberian NPK mutiara sebanyak 0,6 g per tanaman.

Pertumbuhan akar primer dapat diukur melalui panjang akar. Berdasarkan hasil penelitian akar terpanjang terdapat bibit dengan NPK mutiara 0 g per tanaman (Tabel 5). Hal tersebut dipengaruhi oleh pergerakan akar yang dipengaruhi oleh rangsangan bahan kimia yang disebut kemotropisme. Pada perlakuan NPK mutiara 0 g per tanaman, akar tidak diberikan input berupa pupuk sehingga akar terus bergerak mencari unsur hara. Oleh karenaitu pergerakan panjang akar pada perlakuan dosis $0 \mathrm{~g}$ per tanaman lebih panjang dibandingkan dengan perlakuan dosis lainnya. Cara penyiraman atau pengairan tanaman dengan irigasi mampu menyediakan aerasi dan kelembaban tanah yang lebih baik seperti yang terjadi pada penelitian yang dilakukan oleh Intara (2011) bahwa pengolahan tanah minimal beririgasi lebih menunjukkan hasil yang lebih baik pada peningkatan jumlah daun dan panjang akar tanaman cabai.

Kecepatan penyerapan hara pada daun dipengaruhi oleh status hara yang tersedia dalam tanah. Apabila kadar hara dalam tanah rendah, maka penyerapan hara melalui daun relatif lebih cepat (Rosmarkam, 2002). Aplikasi pupuk daun lebih efektif pada fase generatif. Hasil penelitian yang dilakukan oleh Jumini (2009) menunjukkan bahwa aplikasi pupuk daun berpengaruh terhadap panjang dan bobot buah terong per tanaman namun tidak berpengaruh nyata terhadap tinggi tanaman dan jumlah cabang per tanaman.

Interaksi perlakuan berpengaruh terhadap diameter bibit dan bobot basah bibit (Tabel 6). Perlakuan pupuk NPK mutiara 0,6 g per tanaman dengan tanpa aplikasi plant catalyst menghasilkan diameter batang lebih besar dibandingkan dengan perlakuan lain yaitu 3,05 mm. Perlakuan pupuk NPK mutiara 0,6 g per tanaman dengan aplikasi plant catalyst satu kali per minggu menghasilkan bobot basah bibit terberat dibandingkan dengan perlakuan lain yaitu $5,55 \mathrm{~g}$.
Pengelompokan berpengaruh nyata terhadap pertumbuhan tinggi bibit, jumlah daun, panjang daun, lebar daun, diameter batang, bobot basah bibit dan bobot kering bibit. Namun tidak berpengaruh nyata terhadap panjang akar dan jumlah akar sekunder.

\section{KESIMPULAN}

Kesimpulan yang dapat diperoleh dari penelitian yang telah dilakukan ini adalah dosis pupuk NPK 0,6 g per tanaman merupakan dosis paling efisien untuk diberikan terhadap persemaian bibit cabai keriting yang ditunjukkan pada hasil bibit tertinggi dan jumlah daun lebih banyak, sehingga diharapkan bibit dapat lebih siap untuk ditanam pada lahan pertanaman. Frekuensi aplikasi plant catalyst tidak berpengaruh nyata terhadap semua variabel pengamatan sehingga pemberian pupuk daun tidak efisien jika diaplikasikan pada persemaian bibit cabai keriting. Selain itu terdapat interaksi antara dosis pupuk NPK dan aplikasi plant catalyst pada diameter batang dan bobot basah bibit cabai keriting. Kelompok bibit dengan ukuran besar sebagai bahan tanam menunjukkan pertumbuhan yang lebih baik dilihat dari tinggi bibit, jumlah daun, dan diameter batang.

\section{DAFTAR PUSTAKA}

CNI. 2011. Plant catalyst 2006. Meningkatkan produktivitas tanaman. Available online at http:/ /www.cni.co.id/index.php/products-info/productcategory/products- categories/farming/2-plantcatalyst-2006-meningkatkan-produktivitastanaman, [18 Februari 2015].

Direktorat Pangan dan Pertanian. 2014. Studi Pendahuluan, Rencana Pembangunan Jangka Menengah Nasional (RPJMN) Bidang Pangan dan Pertanian 2015-2019. Direktorat Pangan dan Pertanian. Bappenas. Jakarta.

Intara, Z. I, A. Sapei, Erizal, N. Sembiring, dan M.H.B. Djoefrie. 2011. Mempelajari pengaruh pengolahan tanah dan cara pemberian air terhadap pertumbuhan tanaman cabai (Capsicum annuum L). Embryo 8(1): 32-39.

Jumini dan A. Marilah. 2009. Pertumbuhan dan hasil anaman terung akibat pemberian pupuk daun gandasil D dan zat pengatur tumbuh harmonik. Jurnal Floratek. 4: 73-80.

Kurniawan, P.S. 2014. Cara Membuat Arang Sakam. Available online at http://alamtani.com/arangsekam- padi.html, [25 Agustus 2016]. 
Nugroho, H., M.S. Purnomo, Issirep S. 2006. Struktur dan Perkembangan Tumbuhan. Penebar Swadaya. Jakarta. $180 \mathrm{hlm}$

Rosmarkam, A. dan N.W. Yuwono. 2002. Ilmu Kesuburan Tanah. Kanisius. Yogyakarta. 225 hlm.

Rostini, N. 2012. 9 Strategi Bertanam Cabai Bebas Hama dan Penyakit. Agromedia Pustaka. Jakarta Selatan. 98 hlm.

Sumarni, N. dan A. Muharm. 2005. Budidaya Tanaman Cabai Merah. Panduan Teknis PTT Cabai Merah, No.2. Balai Penelitian Tanaman Sayuran. Bandung. $44 \mathrm{hlm}$.
Sutrinah. 2006. Peranan plant catalist 2006 dalam meningkatkan produksi sawi. Jurnal Ilmiah Pertanian 3(1): 6-10.

Venita,Y. dan Armaini. 2007. Pengaruh bokhasi dan nitrogen dalam meningkatkan kualitas bibit cabai merah di pembibitan. Laporan Penelitian. Lembaga Penelitian Universitas Riau. Pekanbaru. 